\title{
Brachial plexus paralysis associated with traumatic asphyxia
}

\author{
Oksan DERINOZ GULERYUZ (10
}

Division of Pediatric Emergency, Department of Child Health and Pediatrics, Faculty of Medicine, Gazi University, Ankara, Turkey. Corresponding Author: Oksan DERINOZ GULERYUZ

E-mail: oderinoz@gazi.edu.tr

Submitted: 14.12.2020 Accepted: 15.02.2021

\section{ABSTRACT}

Traumatic injuries are the most common cause of brachial plexus lesions in children and adults. There are many causes of brachial plexus injuries such as accidents, falls and prolonged pressure. Traumatic asphyxia (TA) is a rare but serious clinical syndrome. Rarely, brachial plexus lesion may develop after TA and it is extremely rare in children. The cause of brachial plexus injury in patients without posttraumatic nerve root avulsion has not yet been fully explained. In this case report, we present the case of a child with neurological damage following TA which is very rare in the literature.

Keywords: Asphyxia, Brachial Plexus, Children, Trauma

\section{INTRODUCTION}

Traumatic asphyxia (TA) or Perthes syndrome is a very rare clinical syndrome that develops after a person is caught between two objects or trapped under heavy furniture. Almost all patients have facial edema, cervicofacial cyanosis, petechiae, subconjunctival hemorrhage and, respiratory distress [1].

The incidence of reported TA in adults is 1 case per 18.500 accidents. However, it is very rare in children and its true incidence is not well known in pediatric population [2].

Rarely, brachial plexus lesions may develop after TA and it is extremely rare in children. In this case report, we present a case of neurological damage following TA in a child.

\section{CASE REPORT}

A 12-year-old male patient, who was followed up for attention deficit hyperactivity syndrome, was brought to the Pediatric Emergency Department after being trapped by an automatic door. It was learned from his history that he played with the automatic door and tried to pass when it was about to close, he was stuck under the door for up to two minutes. The patient reported pain in the right side of his neck and difficulty in moving his right arm. On admission, he was alert and awake. Initial vital signs were stable. Physical examination revealed an excessive number of petechial rashes on the face and upper trunk, subconjunctival hemorrhage (Figure 1) and pain with palpation in the right side of the neck. In the neurological examination, motor deficits in the right shoulder, elbow and wrist in addition to paresthesia of the right forearm were observed. Biceps reflex in the right arm was absent and the triceps reflex was hypoactive. The range of motion of the right shoulder was limited because of pain.

A bedside postero-anterior chest radiography showed a suspicious fracture line in the right clavicle (Figure 2). Cervical radiography (Figure 3), extended focused assessment with sonography for trauma (eFAST) and craniocervical tomography findings were normal. Craniocervical magnetic resonance imaging (MRI) showed edema between the subcutaneous and muscle planes in the right side of the neck and edema in the supraclavicular segment of the $\mathrm{C}_{6}$ nerve root originating from the $\mathrm{C}_{5}-\mathrm{C}_{6}$ intervertebral disc, and no avulsion was detected (Figure 4).

He was evaluated by orthopedics and physical medicine and rehabilitation therapy departments and surgical intervention was not considered. His arm was immobilized. Brachial plexus paralysis secondary to trauma was considered in the patient.

How to cite this article: Guleryuz Derinoz O. Brachial plexus paralysis associated with traumatic asphyxia. Marmara Med J 2021; 34(2):215-218. doi: 10.5472/marumj.944263 
Surgical treatment was not considered due to the absence of avulsion, edema between subcutaneous structures and muscle tissues, and edema in the supraclavicular segment of the $\mathrm{C}_{6}$ nerve root in the MRI examination. He was discharged with antiinflammatory treatment. Two weeks later, no change was detected in the control examination and EMG was planned. Since, EMG was not recommended in cases without avulsion, for our patient we planned EMG before the first month after the trauma. EMG was performed approximately one month after the event and a partial lesion of the upper trunk of the brachial plexus was detected In the right side.

He was followed-up with these findings and physiotherapy was started. There was no significant improvement in his clinical condition at the end of three months follow-up. Surgical intervention was not considered in our patient because no avulsion was detected. The patient left our follow-up after three months of follow-up, so long-term follow-up could not be done.

Written consent was obtained from the patient's family.

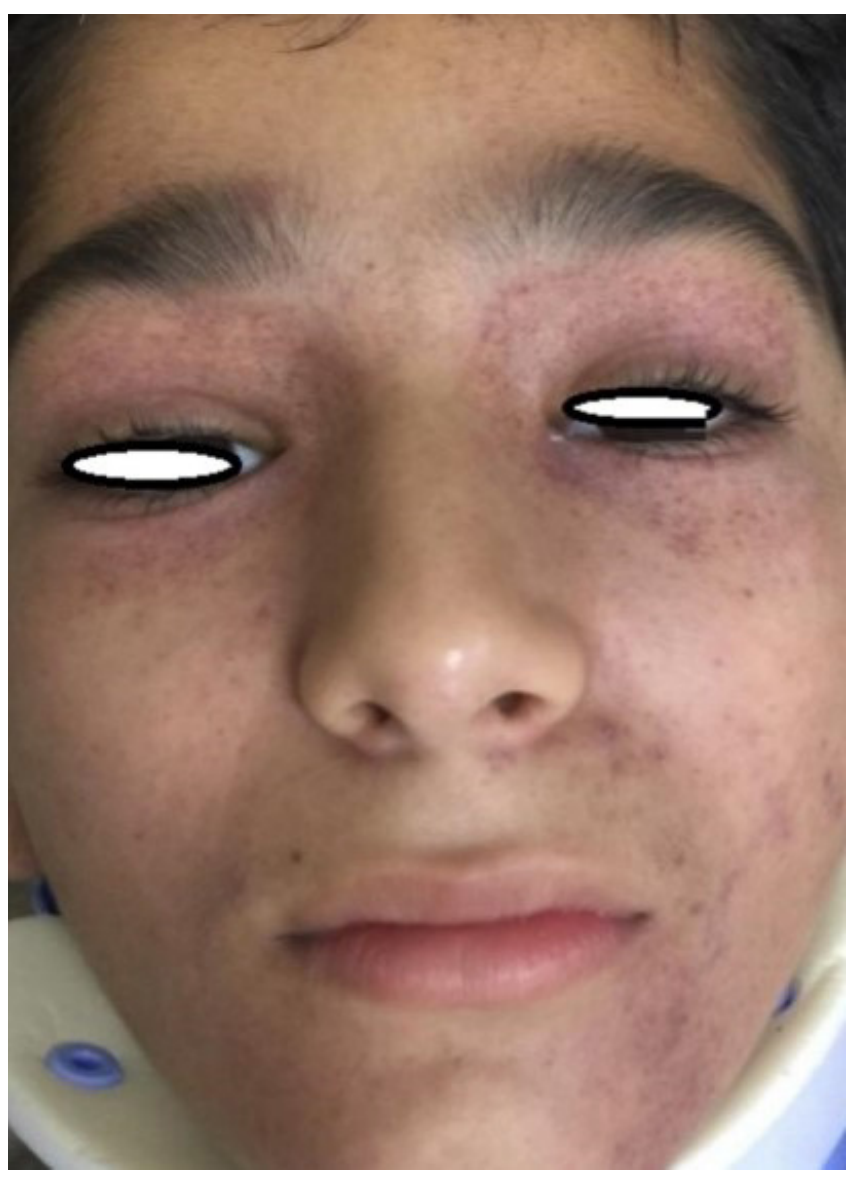

Figure 1. The appearance of the patient's face. A lot of petechiae on his face.

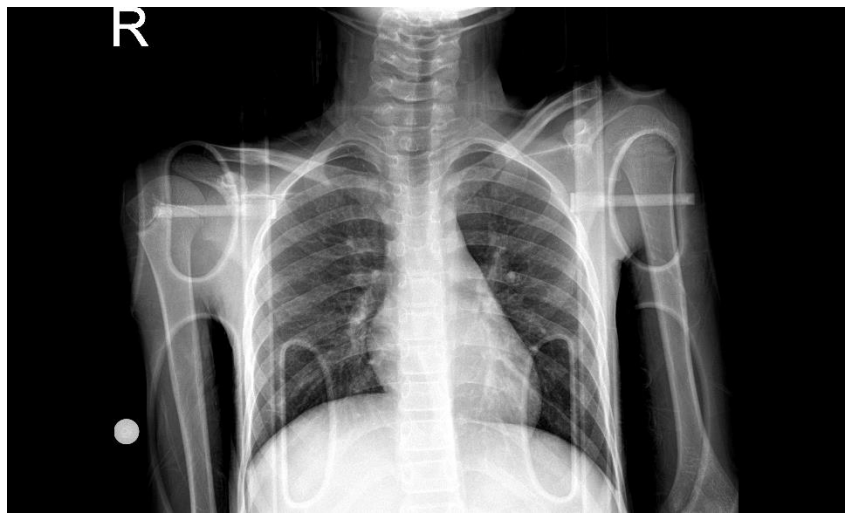

Figure 2. Bedside antero-posterior lung radiography of the patient. Irregularity of cortical bone in the lateral $1 / 3$ of the right clavicle.

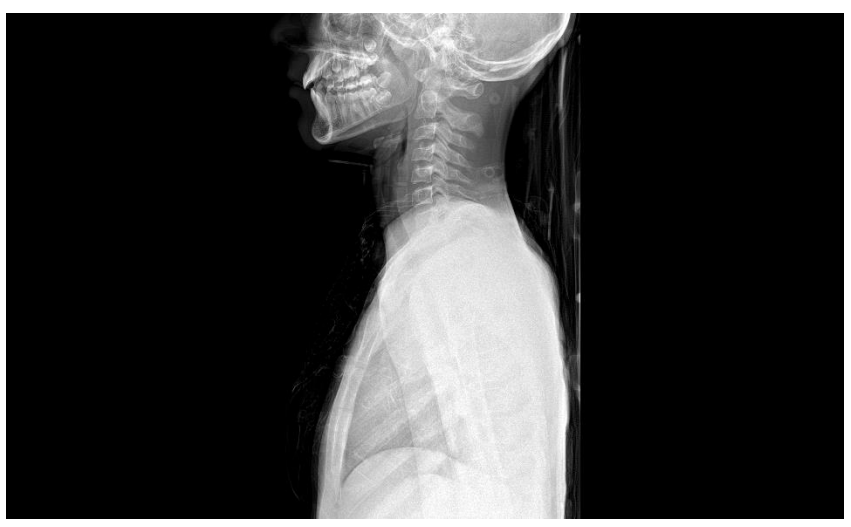

Figure 3. Lateral cervical radiography

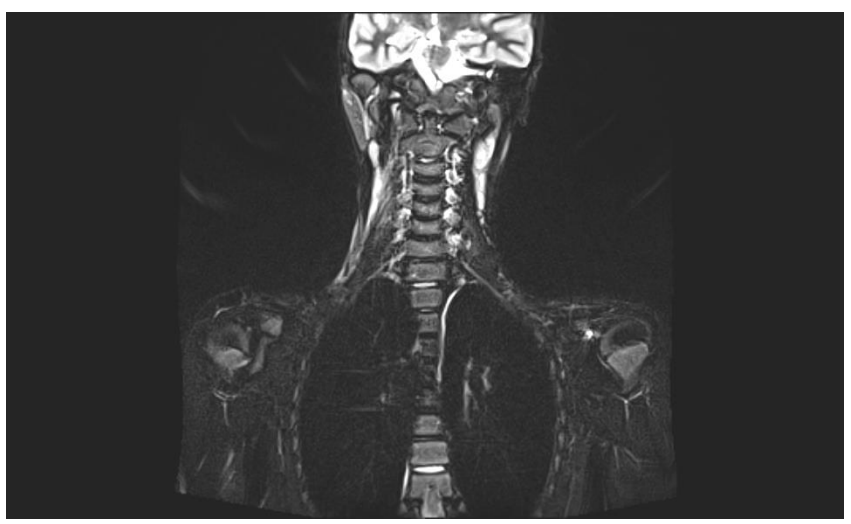

Figure 4. Cervical magnetic resonance imaging of the patient. Edema between the subcutaneous muscle plans on the right side of the neck and the root of the $C_{6}$ nerve. 


\section{DISCUSSION}

Traumatic injuries are the most common cause of brachial plexus paralysis (BPP) in children and adults [3]. Motor vehicle accidents, industrial accidents, objects falling on a shoulder, sports injuries, falls and prolonged pressure on the plexus during deep sleep are among the many causes of brachial plexus injuries $[3,4]$. Rarely, BPP may develop after TA $[5,6]$.

The main pathophysiological mechanism in TA is the increase in the pressure in the thorax due to a sudden and severe force on the chest and upper abdomen resulting in the rapid passage of blood in the right atrium to the valveless jugular and innominate veins in the head and neck region and the occurrence of small bleeding in the vein bed [7]. It is emphasized in the literature that the most likely cause of injury to the brachial plexus may be hypoxia in the injured area due to trauma to the upper body and shoulder, but the effect of hypoxia has not been clearly demonstrated $[2,3]$.

BPP develops according to the underlying causes of compression, transection, ischemia, inflammation, metabolic abnormalities, neoplasia, and radiation therapy in this region. Since, this region is protected under the bone structure, nerve compression rarely occurs by direct compression of this region. Excess transaction of the nerve is also often seen in major trauma due to high-energy traction. The mechanism of trauma causes nerve roots to rupture, leading to the emergence of a clinical condition. Ischemia is a condition caused by obstruction of small intraneural vessels and is a common pathophysiological condition for inflammatory, metabolic and radiation-induced plexopathies. Ischemia causes localized axon damage and denervates muscle and skin receptors [8,9]. In our opinion, as in ischemia-related brachial plexus injuries, intramural vessel occlusion due to the sudden increase in intravenous pressure in TA cases may cause the development of brachial plexus lesions. Also, cytotoxic edema due to hypoxia caused by asphyxia may result in compression of nerve roots. In cases with plexus injury on physical examination, if the mechanism of trauma is appropriate, root avulsions should be considered and excised with imaging methods. Cytotoxic edema caused by hypoxia may be the most important pathophysiologic mechanism in cases where avulsion cannot be detected.

Agitation, loss of consciousness, confusion, or seizures have been reported after TA. It has been reported that this clinical situation develops due to indirect injury after anoxic damage, ischemia or increased vascular pressure and cerebral edema secondary to venous obstruction [10-12].

Traumatic asphyxia has almost good prognosis, if the compression is brief $[2,13]$. In cases without accompanying injuries death may occur due to prolonged compression, hypoxia and apnea. It heals spontaneously within weeks except the neurological and ocular signs $[1,14,15]$. There is no clear information about the follow-up period of these cases in the literature. Because the course of the disease depends on the severity of the trauma and accompanying additional injuries, it is appropriate to determine the follow-up period for each patient $[1,16]$.
The number of BPP patients with TA is very few and most of them are adult cases. Neurological abnormalities were reported in $85 \%$ (29 patient) of 34 patients with neurological sequelae (loss of consciousness, brachial plexopathy, visual disturbances, paralysis, confusion, seizures) who were evaluated as TA; BPP in seven cases $(21 \%)$. Three patients had mild residual muscle weakness, while others recovered completely [5]. In this study, no information was given about the follow-up period of these patients. However, it is reported in the literature that mild neurological findings usually regress within $24-48$ hours [1012].

In a study in which $14 \mathrm{TA}$ cases were evaluated, it was reported that a 42 -year-old patient developed post-traumatic consciousness, blindness, confusion and BPP and neurological improvement was 15 months later. In this case series, no pediatric cases with BPP after TA were reported. Follow-up was established for all 14 patients from 6 to 117 months (mean, 41 monts). There was no long-term disability related to TA and there were no late sequelae releated to neurologic abnormalities. [5]. Since, our case was out of follow-up after three months of follow-up, its long-term effects could not be followed.

In our case, BPP was developed after TA which was not reported before in a pediatric case in the literature according to our knowledge. Brachial plexus injury is a condition that can occur with many different mechanisms. Brachial plexus injuries are of four types: avulsion, rupture, axonogenesis, and neuropraxia [17]. While lesions such as axonogenesis and neuropraxia heal spontaneously, avulsion injuries cannot heal spontaneously [18]. These injuries should be differentiated before treatment. Generally, surgical treatment is required if no improvement is noted within 2-3 months. Since, primary repair of avulsion injury is not possible, the option of nerve reconstruction should be considered [19].

As a conclusion, cytotoxic edema caused by asphyxia without avulsion of nerve roots after trauma can cause BPP. We made the diagnosis of BPP that developed after trauma in our patient with the results of EEG and MRI examinations after clinical evaluation. In our case, no avulsion was detected with the MR results. Surgical intervention was not considered in our patient because no avulsion was detected. Follow-up was taken with the physical therapy and rehabilitation plan. However, the family left the hospital follow-up after three months of follow-up. However, the absence of avulsion should be demonstrated by radiological methods and the patient should be monitored for long-term sequelae. The period of monitoring should be decided according to the patient's clinical status.

Declaration of conflicting interests: The author declared no potential conflicts of interest with respect to the article, authorship, and/or publication of this article.

Funding: The author received no financial support for the research, authorship, and/or publication of this article.

Informed consent: Written informed consent was obtained from patient's father for anonymized patient information to be published in this article. 
Human rights: All procedures were performed in accordance with basic ethical principles.

\section{REFERENCES}

[1] Karamustafaoglu YA, Yavasman I, Tiryaki S, Yoruk Y. Traumatic asphyxia. Int J Emerg Med 2010; 3: 379-80. doi: $10.1007 / \mathrm{s} 12245.010 .0204-\mathrm{x}$

[2] Montes-Tapia F, Barreto-Arroyo I, Cura-Esquivel I, Rodríguez-Taméz A, de la O-Cavazos M. Traumatic asphyxia. Pediatr Emerg Care 2014;30:114-6. doi: 10.1097/ PEC.000.000.0000000067.

[3] Wilbourn AJ. Plexopathies. Neurol Clin 2007;25 :139-71. doi: 10.1016/j.ncl.2006.11.005.

[4] Fourcade G, Taieb G, Renard D, Labauge P, Pradal-Prat D. Brachial plexus sleep palsy. Rev Neurol (Paris) 2011;167(67):522-5. doi: 10.1016/j.neurol.2010.10.005.

[5] Jongewaard WR, Cogbill TH, Landercasper J. Neurologic consequences of traumatic asphyxia. J Trauma 1992;32:28-31. doi: 10.1097/00005.373.199201000-00006.

[6] Sandiford JA, Sickler D. Traumatic asphyxia with severe neurologic sequale. J Trauma 1974:14:805-10. doi: 10.1097/00005.373.197409000-00011.

[7] Gorenstein L, Blair GK, Shandling B. The prognosis of traumatic asphyxia in childhood. J Pediatr Surg 1986; 21: 7536. doi: 10.1016/s0022-3468(86)80358-x

[8] Jaeckle KA. Neurological manifestations of neoplastic and radiation-induced plexopathies. Semin Neurol 2004;24:38593. doi: $10.1055 / \mathrm{s}-2004-861533$

[9] Dyck PJ, Windebank AJ. Diabetic and nondiabetic lumbosacral radiculoplexus neuropathies: New insights into pathophysiology and treatment. Muscle Nerve 2002;25:47791. doi: 10.1002/mus.10080

[10] Choi YJ, Lee SJ, Kim Hj, et al. Bilateral retrobulbar hemorrhage and visual loss following traumatic asphyxia. Korean J Ophthalmol 2010;24:380-3. DOI: 10.3341/kjo.2010.24.6.380

[11] Rosato RM, Shapiro MJ, Keegan MJ, et al. Cardiac İnjury complicating traumatic asphyxia. J Trauma 1991; 31: 1387-89. doi: 10.1097/00005.373.199110000-00012

[12] Sarihan H, Abes M, Akyazici R, et al. Traumatic asphyxia in children. J Cardiovasc Surg (Torino) 1997; 28:93-95.

[13] Dunne JR, Shaked G, Golocovsky M. Traumatic asphyxia: an indicator of potentially severe trauma. Injury 1996;27:746-9 doi: 10.1016/s0020-1383(96)00113-1.

[14] Hurtado T. R., Della-Giustina D. A. Traumatic asphyxia in a 6-year-old boy. Pediatric Emergency Care 2003;19:167-8. doi: 10.1097/00006.565.200306000-00007.

[15] Ertok I, Kurtoglu Çelik G, Ercan Haydar G, Karakayali O, Yılmaz M, Erşen T. Review of traumatic asphyxia syndrome with a case presentation. J Acad Emerg Med Case Rep 2013;4:58-61. doi: 10.5505/jaemcr.2013.32448.

[16] Derinoz-Guleryuz O, Akar T, Men-Atmaca Y. Four traumatic asphyxial cases with an "Masque Ecchymotique" in Pediatric Emergency Department. J Pediatr Emerg Intensive Care Med 2020;7:92-96 doi: 10.4274/cayd.galenos.2019.73383

[17] Birch R. Brachial plexus injury: the London experience with supraclavicular traction lesions. Neurosurg Clin N Am 2009;20:15-23. doi: 10.1016/j.nec.2008.08.002.

[18] Doi K. Obstetric and traumatic pediatric palsy. In: Peimer CA, ed. Surgery of the Hand and Upper Extremity, New York: McGraw-Hill, 1996:1443-63.

[19] Armangil M. Brakial pleksus yaralanmalarina yaklaşim. 2014; 5: 136-40. (Article in Turkish) doi:10.5152/tcb.2013.021 